\title{
Correlation between Retinal Vessel Calibre and Neurodegeneration in Patients with Type 2 Diabetes Mellitus in the European Consortium for the Early Treatment of Diabetic Retinopathy (EUROCONDOR)
}

\author{
Ulrik Frydkjaer-Olsen ${ }^{a, b}$ Rasmus Soegaard Hansen ${ }^{a, b}$ Rafael Simóc \\ José Cunha-Vaz ${ }^{d}$ Tunde Peto $^{b, e}$ Jakob Grauslund ${ }^{a, b}$ on behalf of the \\ EUROCONDOR
}

\begin{abstract}
a Department of Ophthalmology, Odense University Hospital, and ${ }^{b}$ Department of Clinical Research, University of Southern Denmark, Odense, Denmark; ' Diabetes and Metabolism Research Unit, Institut de Recerca Hospital Universitari Vall d'Hebron (VHIR), Barcelona, Spain; ${ }^{d}$ Association for Innovation and Biomedical Research on Light and Image (AIBILI) and University of Coimbra, Coimbra, Portugal; eNIHR Biomedical Research Centre, Moorfields Eye Hospital NHS Foundation Trust and UCL Institute of Ophthalmology, London, UK
\end{abstract}

\section{Key Words}

Retinal vessel calibre · Neurodegeneration · Type 2 diabetes mellitus

\section{Abstract \\ Purpose: To investigate the correlation between retinal ves- sel calibre and measurements of neurodegeneration in pa- tients with type 2 diabetes (T2D) and no or early diabetic retinopathy (DR). Methods: Baseline data on 440 patients with T2D from the EUROCONDOR clinical trial were used. DR was graded according to the Early Treatment of Diabetic Ret- inopathy Study (ETDRS) scale, and patients with ETDRS levels 10-35 were included. Retinal vessel diameters were mea- sured by semi-automatic software. Calibres were summa- rized into central retinal artery and vein equivalents (CRAE and (RVE). Results: Median age and diabetes duration were 64.0 and 10.3 years, respectively. ETDRS levels were 10 (42.3\%), 20 (27.5\%) and 35 (30.2\%). The median CRAE and CRVE were 146.7 and $215.3 \mu \mathrm{m}$, respectively. CRAE did not differ according to ETRDS level $(p=0.12)$, but wider CRVE}

\begin{tabular}{ll}
\hline KARGER & $\begin{array}{l}\text { ( } 2016 \text { The Author(s) } \\
\text { Published by S. Karger AG, Basel } \\
\text { Openger }\end{array}$ \\
E-Mail karger@karger.com & $0030-3747 / 16 / 0561-0010 \$ 39.50 / 0$ \\
www.karger.com/ore & This article is licensed under the Creative Commons Attribution- \\
& NonCommercial-NoDerivatives 4.0 International License (CC BY- \\
& NC-ND) (http://www.karger.com/Services/OpenAccessLicense). \\
& Usage and distribution for commercial purposes as well as any dis- \\
& tribution of modified material requires written permission.
\end{tabular}

were found in patients with higher ETDRS levels $(p=0.04)$. In a multivariable linear regression model, CRAE was associated with macular ganglion cell layer thickness (coefficient 0.27 per micrometre, $\mathrm{p}<0.01$ ), and CRVE was correlated with macular retinal thickness (coefficient -0.07 per micrometre, $p=0.04$ ) and retinal nerve fibre layer thickness at the optic disc (coefficient 0.32 per micrometre, $p<0.01$ ). Conclusion: Retinal vessel calibre was independently associated with structural changes of the neuroretina in patients with no or early DR.

(c) 2016 The Author(s)
Published by S. Karger AG, Basel

\section{Introduction}

More than 382 million people have diabetes mellitus (DM), and the number affected is increasing dramatically with an expected number of patients of 592 million by 2035 [1]. Diabetic retinopathy (DR) is a frequent and potentially blinding ocular complication and a leading cause of vision loss in working-age people [2]. For many years 
DR has been described as a microvascular complication, but more recent findings suggest that neurodegeneration plays an important role in the pathogenesis of DR [3-5]. Different neurogenic factors have been investigated, and the interaction between neural activity and regulation of blood flow, described as the neurovascular coupling, has been suggested to be involved in the mechanism of the disease [6].

Retinal vessel calibre can be measured non-invasively by semi-automatic software $[7,8]$. Several studies have found a relation between retinal vessel calibre and microand macrovascular complications in patients with DM [9-13], and in a prospective study it was demonstrated that narrower arteriolar and wider retinal venular diameters predict long-term nephropathy, peripheral neuropathy and proliferative DR [14].

Retinal neurodegeneration can be assessed clinically. Multifocal electroretinography (mf-ERG) examines functional parameters, while optical coherence tomography (OCT) measures the structural composition of the neuroretina.

Retinal vessel calibre analysis combined with functional and structural examinations of retinal neurodegeneration can reveal new aspects of the complex neurovascular interaction. Only a few clinical studies that included retinal vessel calibre measurements have investigated neurovascular characteristics in patients with diabetes [15-18]. However, these studies were limited by a low sample size or did not investigate the association between retinal vasculature and parameters related to neurodegeneration as primary end point.

Given that retinal vascular calibre changes are an early, and often even preclinical, sign of vascular damage in diabetes [14], we speculate that the subtle interplay between vascular and neurogenic damage may be an early indicator of retinal impairment. Hence, the aim of the present study was to investigate the correlations between retinal vessel calibre and neurodegeneration measurements in patients with type $2 \mathrm{DM}$ (T2DM) and no or minimal DR.

\section{Methods}

\section{Study Population}

The European Consortium for the Early Treatment of Diabetic Retinopathy [EUROCONDOR, NCT01726075 (278040)] is a multicentre, 2-year prospective, interventional, phase II-III, randomized controlled clinical trial [6]. The primary objective was to assess the efficacy of topically administered neuroprotective drugs (somatostatin and brimonidine) in order to prevent or arrest neurodegenerative changes. Baseline data of 449 patients with T2DM was obtained between February 2013 and February 2014 at 11 Eu- ropean sites. One study eye was identified in each patient. Only eyes with no or minimal DR (Early Treatment of Diabetic Retinopathy Study, ETDRS, levels 10, 20 and 35) were included. In addition, inclusion criteria were duration of T2DM for at least 5 years and age between 45 and 75 years. Conversely, exclusion criteria were previous laser photocoagulation, retinal diseases that cause degeneration (e.g. glaucoma) and refractive error more than or equal to $\pm 5 \mathrm{dpt}$. Eyes with blurred ocular media or inadequate pupil dilatation that prevented good-quality fundus photography were excluded. Patients with renal failure or $\mathrm{HbA}_{1 \mathrm{c}}>86 \mathrm{mmol} / \mathrm{mol}$ in the previous 6 months were also excluded.

The study was approved by the European Commission (FP7HEALTH-2011) and was conducted in accordance with the principles of the Helsinki II Declaration. Approval from the local scientific ethical committees of each centre was obtained, and all patients gave written informed consent.

\section{Baseline Examinations}

Examinations were performed according to the EUROCONDOR protocol and by certified technicians only. A full medical history including duration of T2DM and information about presence of any diabetic complications such as nephropathy and neuropathy was obtained from medical records. Best-corrected visual acuity was measured, and a full ophthalmic examination was performed.

Laboratory tests included the measurements of $\mathrm{HbA}_{1 \mathrm{c}}$, cholesterol, triglyceride, creatinine, glomerular filtration rate, albuminuria and the albumin/creatinine ratio. Furthermore, blood pressure, height and weight were measured, and the body mass index was calculated.

Identification of the study eye, and gradings of colour fundus photographs, OCT and $\mathrm{mf}-\mathrm{ERG}$ were done by a central reading centre (the Coimbra Ophthalmology Reading Centre).

\section{Fundus Examination}

Mydriatic Topcon cameras (i.e. TRC-50IA, -50IX, -50EX, -50DX, -50DX Type IA and NW6S, Topcon, Tokyo, Japan) and a Zeiss camera (FF450 PLUS IR, Carl Zeiss Meditec, Jena, Germany) were used to acquire 30- to 35-degree modified 7-field colour fundus photographs of both eyes after pupillary dilatation with tropicamide (10 $\mathrm{mg} / \mathrm{ml}$ ) and phenylephrine (10\%). Fields 1 and 3 were modified from the 7 ETDRS standard fields to include the centre of the macula. The level of DR was graded according to the ETDRS protocol [19].

\section{Structural Neurodegeneration}

Topcon 3D OCT-2000 Spectral Domain OCT (Topcon; available at 4 clinical sites) and Zeiss Cirrus HD-OCT (Carl Zeiss Meditec; available at 7 clinical sites) were used to measure the macular retinal thickness, the macular ganglion cell layer (GCL) thickness and the retinal nerve fibre layer (RNFL) thickness at the optic disc. Different scan protocols and segmentation algorithms between instruments were used as previously documented [20].

To examine the differences between Topcon $(n=162)$ and Zeiss equipment $(\mathrm{n}=278)$, we tested for the mean values of macular retinal thickness, macular GCL thickness and RNFL thickness at the optic disc. Patients who were examined by Zeiss OCT had a higher macular retinal thickness $(265.20$ vs. $238.62 \mu \mathrm{m}, \mathrm{p}<0.01)$ and macular GCL (79.21 vs. $66.19 \mu \mathrm{m}, \mathrm{p}<0.01)$ but a lower RNFL thickness at the optic disc $(89.08$ vs. $95.99 \mu \mathrm{m}, \mathrm{p}<0.01)$. In order to address the differences, a conversion factor (mean Zeiss value 
Table 1. Clinical characteristics (median values) of patients with T2DM overall and according to the ETDRS scale, levels 10, 20 and 35

\begin{tabular}{|c|c|c|c|c|c|}
\hline & $\begin{array}{l}\text { Overall } \\
(\mathrm{n}=440)\end{array}$ & $\begin{array}{l}\text { Level } 10 \\
(\mathrm{n}=186)\end{array}$ & $\begin{array}{l}\text { Level } 20 \\
(\mathrm{n}=121)\end{array}$ & $\begin{array}{l}\text { Level } 35 \\
(\mathrm{n}=133)\end{array}$ & $\begin{array}{l}\mathrm{p} \\
\text { for trend }\end{array}$ \\
\hline Age, years & 64.0 & 65 & 63 & 63 & $<0.01$ \\
\hline Sex, $\%$ male & 66.1 & 71.0 & 62.0 & 63.2 & 0.15 \\
\hline Duration of diabetes, years & 10.3 & 9.3 & 10.2 & 13.2 & $<0.01$ \\
\hline Systolic blood pressure, $\mathrm{mm} \mathrm{Hg}$ & 135 & 132 & 138 & 136 & 0.09 \\
\hline Diastolic blood pressure, $\mathrm{mm} \mathrm{Hg}$ & 78 & 77 & 77 & 78 & 0.81 \\
\hline \multicolumn{6}{|l|}{$\mathrm{DR}, \%$} \\
\hline ETDRS level 10 & 42.3 & & & & \\
\hline ETDRS level 20 & 27.5 & & & & \\
\hline ETDRS level 35 & 30.2 & & & & \\
\hline $\mathrm{HbA}_{1 \mathrm{c}}, \%$ & 7.0 & 6.8 & 6.9 & 7.3 & $<0.01$ \\
\hline mf-ERG implicit time (mean of rings $1-6$ ), ms & 36.6 & 36.8 & 36.6 & 36.6 & 0.93 \\
\hline mf-ERG amplitude (mean of rings $1-6), \mathrm{nV} /$ degree $^{2}$ & 43.4 & 44.5 & 41.2 & 42.1 & 0.02 \\
\hline Retinal thickness in macula, $\mu \mathrm{m}$ & 265 & 263 & 268 & 265 & 0.13 \\
\hline Macular GCL thickness, $\mu \mathrm{m}$ & 79 & 79 & 80 & 79 & 0.91 \\
\hline RNFL thickness at optic disc, $\mu \mathrm{m}$ & 90 & 90 & 91 & 88 & 0.54 \\
\hline $\mathrm{CRAE}, \mu \mathrm{m}$ & 146.7 & 144.5 & 148.0 & 148.2 & 0.12 \\
\hline CRVE, $\mu \mathrm{m}$ & 215.3 & 214.5 & 213.2 & 216.6 & 0.04 \\
\hline
\end{tabular}

$\mathrm{p}$ for trend: Cuzick's test for trend was used; $\mathrm{p}<0.05$ was considered statistically significantly different.

divided by mean Topcon value) was then added for Topcon measurements throughout the analysis (given that Topcon was used only at 4 sites). Conversion factors were $1.11,1.20$ and 0.93 for macular retinal thickness, macular GCL thickness and RNFL thickness at the optic disc, respectively.

\section{Functional Neurodegeneration}

A RETI-scan mf-ERG system (Roland Consult, Brandenburg a.d. Havel, Germany) was used to measure implicit time and amplitudes of rings 1-6. The examined retinal area equivalent to $46.4^{\circ}$ was arranged in 103 hexagons and divided into 6 rings, ring 1 being the central area. $\mathrm{mf}-\mathrm{ERG}$ examination was performed based on the International Society for Clinical Electrophysiology of Vision standard for clinical mf-ERG [21].

\section{Retinal Vessel Calibre Analysis}

Modified field 1 images including the optic disc of the study eye were analysed with semi-automatic software (IVAN, Department of Ophthalmology Visual Science, University of Wisconsin, Madison, Wis., USA). The software automatically detected the optic disc and traced vessel diameter in a zone 0.5-1.0 disc diameters from the disc margin. Calibres were summarized into central retinal artery and vein equivalents (CRAE and CRVE) according to the 'Big 6 formula' that included only the 6 largest arterioles and venules [7]. One certified grader (U.F.-O.) performed the retinal vascular calibre analysis of the study eye according to a validated protocol $[8,22]$.

\section{Statistical Methods}

Statistical analyses were performed with STATA 14 (StataCorp LP, College Station, Tex., USA), and a $\mathrm{p}$ value $<0.05$ was consid- ered statistically significant. Categorical data were presented as percentages, and continuous data were presented as medians (with range). A univariable linear regression model with CRAE and CRVE as the dependent variables was used to study possible associations between the retinal vasculature and clinical measures. Pearson's r correlation coefficient was used to test for correlations. The Mann-Whitney test was used to test for differences in continuous data between two groups, and Cuzick's test for trend was used to test for trend in differences between several groups. Neurogenic parameters from mf-ERG (mean of rings 1-6) and OCT were subsequently used in a multivariable linear regression model with CRAE and CRVE as the dependent variables. The multivariable analysis was adjusted for age, sex, duration of diabetes, diastolic and systolic blood pressure, level of $\mathrm{DR}, \mathrm{HbA}_{1 \mathrm{c}}$ and CRAE or CRVE, conversely.

\section{Results}

Baseline data included images of 449 patients. Nine patients had either ungradable images $(n=4)$ or less than 6 detectable retinal arterioles and venules $(n=5)$. For the remaining 440 patients, median age and duration of T2DM were 64.0 and 10.3 years, respectively, and $66.1 \%$ were men. ETDRS levels were 10 (42.3\%), $20(27.5 \%)$ and 35 (30.2\%). Median CRAE and CRVE were $146.7 \mu \mathrm{m}$ (range 110.4-196.0 $\mu \mathrm{m}$ ) and $215.3 \mu \mathrm{m}$ (range 160.0-290.8 $\mu \mathrm{m})$, respectively (table 1 ).
Frydkjaer-Olsen et al. 
Table 2. Overall univariable and multivariable linear regression models with CRAE and CRVE as the dependent variables

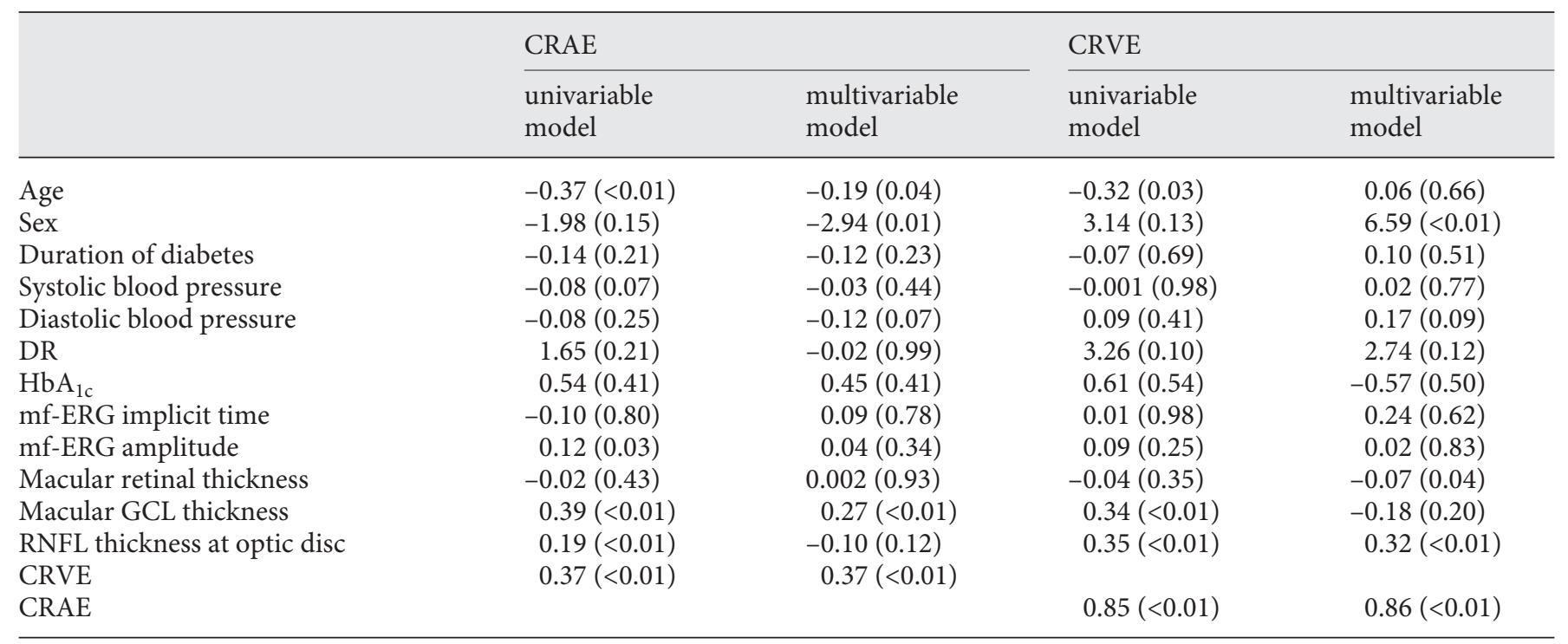

The multivariable model includes age, sex, duration of diabetes, systolic and diastolic blood pressure, DR, HbA $1 \mathrm{c}, \mathrm{mean}_{\mathrm{mf}-\mathrm{ERG}}$ implicit time, mean mf-ERG amplitude, macular retinal thickness, macular GCL thickness, RNFL thickness at the optic disc, and CRVE or CRAE. Figures in parentheses indicate $\mathrm{p}$ values; $\mathrm{p}<0.05$ was considered statistically significantly different.

Patients with higher ETDRS levels of DR were younger $(\mathrm{p}<0.01)$, had a longer duration of T2DM $(\mathrm{p}<0.01)$, higher $\mathrm{HbA}_{1 \mathrm{c}}(\mathrm{p}<0.01)$, lower mf-ERG mean amplitudes of rings $1-6(p=0.02)$ and wider CRVE $(p=0.04$; table 1$)$. On the other hand, CRAE did not significantly differ according to the level of DR ( $\mathrm{p}=0.12)$.

In a univariable model (table 2), CRAE correlated with age (coefficient -0.37 per year, $\mathrm{p}<0.01$ ), mf-ERG amplitude mean of rings $1-6$ (coefficient 0.12 per nanovolts/ squared degree, $p=0.03$ ), macular GCL thickness (coefficient 0.39 per micrometre GCL thickness, $\mathrm{p}<0.01$; fig. 1), RNFL thickness at the optic disc (coefficient 0.19 per micrometre RNFL thickness, $\mathrm{p}<0.01$ ) and CRVE (coefficient 0.37 per micrometre CRVE, $\mathrm{p}<0.01)$. CRVE correlated with age (coefficient -0.32 per year, $p=0.03$ ), macular GCL thickness (coefficient 0.34 per micrometre GCL thickness, $\mathrm{p}<0.01$ ), RNFL thickness at the optic disc (coefficient 0.35 per micrometre RNFL thickness, $\mathrm{p}<$ 0.01; fig. 2) and CRAE (coefficient 0.85 per micrometre CRAE, $\mathrm{p}<0.01$ ). Retinal vessel calibre was not correlated with gender, body mass index, duration of diabetes, $\mathrm{HbA}_{1 \mathrm{c}}$, blood pressure, dyslipidaemia, presence of other diabetic complications (i.e. presence of nephropathy and neuropathy) or any other OCT and mf-ERG parameters.

In an overall multivariable linear regression model (table 2), CRAE was associated with age (coefficient -0.19 per year, $\mathrm{p}=0.04$ ), sex (coefficient -2.94 for females vs. males, $\mathrm{p}=0.01$ ), macular GCL thickness (coefficient 0.27 per micrometre GCL thickness, $\mathrm{p}<0.01$ ) and CRVE (coefficient 0.37 per micrometre CRVE, $p<0.01$ ). CRVE was correlated with sex (coefficient 6.59 for females vs. males, $\mathrm{p}<0.01$ ), macular retinal thickness (coefficient -0.07 per micrometre retinal thickness, $\mathrm{p}=0.04)$, RNFL thickness at the optic disc (coefficient 0.32 per micrometre RNFL thickness, $\mathrm{p}<0.01$ ) and CRAE (coefficient 0.86 per micrometre CRAE, $\mathrm{p}<0.01$ ).

In clinical terms, each year increment of age was correlated with a decrease in CRAE by $-0.19 \mu \mathrm{m}$, female gender was associated with a decrease in CRAE by $-2.94 \mu \mathrm{m}$, each micrometre increment of macular GCL thickness was correlated with an increase in CRAE by $0.27 \mu \mathrm{m}$ and each micrometre increment of CRVE was correlated with an increase in CRAE by $0.37 \mu \mathrm{m}$. Regarding retinal venular calibre, male gender was correlated with an increase in CRVE by $6.59 \mu \mathrm{m}$, each micrometre increment of macular retinal thickness was associated with an decrease in CRVE by $0.07 \mu \mathrm{m}$, each micrometre increment of RNFL thickness at the optic disc was associated with an increase in CRVE by $0.32 \mu \mathrm{m}$, and each micrometre increment of CRAE was correlated with an increase in CRVE by 0.86 $\mu \mathrm{m}$. 


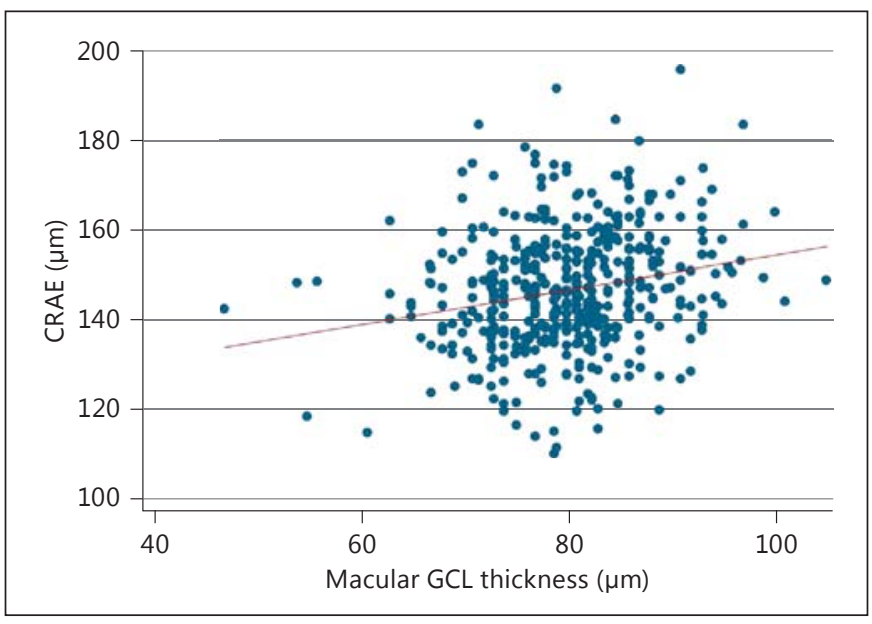

Fig. 1. Correlation between CRAE and GCL thickness among 440 patients with T2DM and no or minimal DR $(\mathrm{r}=0.21, \mathrm{p}<0.01)$.

\section{Discussion}

In this cross-sectional study of patients with T2DM without DR or with only early stages of $\mathrm{DR}$, retinal vessel calibre was independently associated with structural, but not functional, retinal neurodegeneration. Retinal arteriolar calibre was positively correlated with macular GCL thickness, and retinal venular calibre correlated negatively with macular retinal thickness and positively with RNFL thickness at the optic disc.

The impairment of neurovascular coupling preceded the overt micro-angiopathy which could be detected by funduscopic examination. Endothelial cells, glial cells, neural cells, and pericytes are all interacting and participating in the neurovascular unit and may therefore contribute to changes in the retinal vasculature and retinal vessel calibre [6]. Wider arterioles may originate from high blood flow and increased oxygen resources. Correspondingly, wider retinal venular calibres may be caused by impaired vascular autoregulation and ischaemia or appear because of increased blood pressure.

Previous cross-sectional clinical studies found that wider retinal venular diameters were associated with presence of DR, and narrower arteriolar calibres were correlated with severer DR [18, 23-26]. In contrast, prospective studies showed controversial results. In this regard, whereas Broe et al. [14] reported that narrower retinal arterioles were able to predict proliferative DR, Cheung et al. [27] and Alibrahim et al. [28] found that a wider arteriolar calibre was predictive of the development

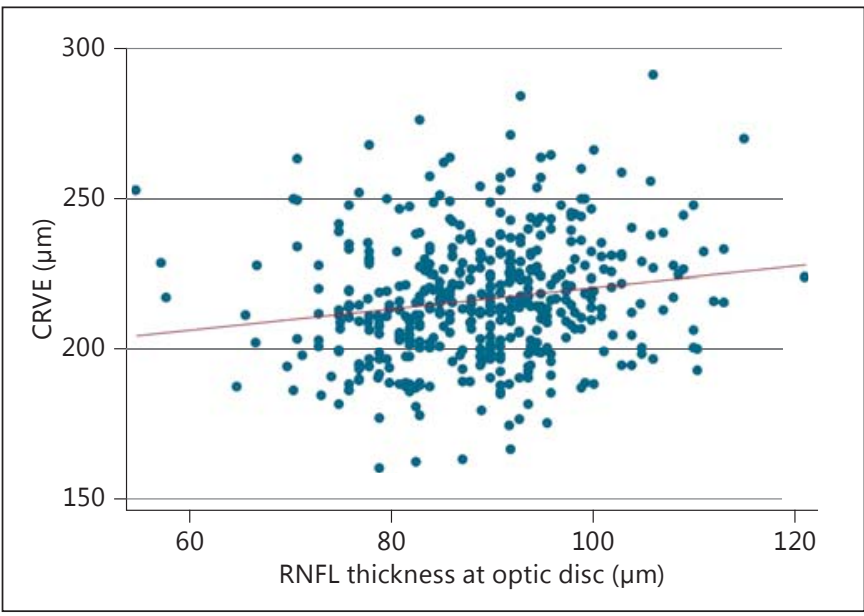

Fig. 2. Correlation between CRVE and RNFL thickness at the optic disc among 440 patients with T2DM and no or minimal DR ( $\mathrm{r}=$ $0.17, \mathrm{p}<0.01)$.

of DR. Prospective studies also showed that wider venular calibres were associated with progression of DR or could predict incident proliferative DR [29, 30]. This has even been prospectively demonstrated in a long-term followup study [14].

In the present study we provide evidence that CRAE correlated positively with macular GCL thickness in early stages of DR. This has not been previously reported and suggests a unique relationship between the macular ganglion cells and the retinal arteriolar diameters. The follow-up of the patients included in the EUROCONDOR study could answer the question whether this relationship is maintained in more advanced stages of DR.

We have found a negative correlation between CRVE and macular retinal thickness. In contrast, in a smaller study Harrison et al. [18] did not find correlations between retinal thickness and retinal vessel calibres in patients with T2DM and no, mild or moderate DR. Overall, our findings suggest that venules are impaired earlier than arterioles in DR and that this event is related to neurodegeneration. In addition, our results point to CRVE as a potential biomarker of retinal neurodegeneration.

CRVE was also positively associated with RNFL thickness at the optic disc. In an earlier study by van Dijk et al. [31], thinning of RNFL was found in 25 patients with minimal DR as compared to participants with no diabetes. However, these measurements were conducted at the central and peripheral macula and, thus, do not compare directly with our finding. As with the association between CRAE and macular GCL, we speculate that our finding
14 
could indicate a link between vascular changes and neurodegeneration in early DR. Future studies will tell whether this connection is also found in the more advanced stages of DR.

In our study, we have identified novel and specific associations between non-invasive vascular markers and early neurodegeneration in a large group of patients with T2DM with no or early DR. Future studies will be needed to establish the cause-effect relationship between retinal vascular calibres and neurodegeneration in early DR.

\section{Appendix}

Members of the European Consortium for the Early Treatment of Diabetic Retinopathy (EUROCONDOR) which have contributed to this paper: F. Bandello (Scientific Institute San Raffaele, Italy), J. Cunha-Vaz and M.A. Costa (Association for Innovation and Biomedical Research on Light and Image, Portugal), C. Egan (Moorfields Eye Hospital, UK), J. García-Arumí (Vall d’Hebron University Hospital, Spain), J. Gibson (University of Aston, UK), S. Harding (University of Liverpool, UK), S. Karadeniz (Interna- tional Diabetes Federation, Europe Region, IDF Europe), G. Lang (University of Ulm, Germany), P. Massin (Hôpital LariboisièreAPHP, France), E. Midena (University of Padova, Italy), B. Ponsati (BCN Peptides, Spain), M. Porta (University of Turin, Italy), P.H. Scanlon and S.J. Aldington (Cheltenham General Hospital, UK), R. Simó and C. Hernández (Vall d'Hebron Research Institute, Spain), J. Grauslund (Odense University Hospital, Denmark).

\section{Acknowledgements}

This project has received funding from the European Union's Seventh Framework Programme for research, technological development and demonstration under grant agreement No. 278040. U.F.-O. was supported by Fight for Sight Denmark, the Region of Southern Denmark and the University of Southern Denmark. T.P. was supported by the NIHR BMRC at Moorfields Eye Hospital NHS Foundation Trust and UCL Institute of Ophthalmology.

\section{Disclosure Statement}

No potential conflicts of interest relevant to this article were reported.

\section{References}

1 Guariguata L, Whiting DR, Hambleton I, Beagley J, Linnenkamp U, Shaw JE: Global estimates of diabetes prevalence for 2013 and projections for 2035. Diabetes Res Clin Pract 2014; 103:137-149.

2 Cheung N, Mitchell P, Wong TY: Diabetic retinopathy. Lancet 2010;376:124-136.

-3 Simo R: Neurodegeneration as an early event in diabetic retinopathy. Endocrinol Nutr 2011;58:211-213.

-4 Abcouwer SF, Gardner TW: Diabetic retinopathy: loss of neuroretinal adaptation to the diabetic metabolic environment. Ann NY Acad Sci 2014;1311:174-190.

5 Simo R, Hernandez C; European Consortium for the Early Treatment of Diabetic Retinopathy: Neurodegeneration is an early event in diabetic retinopathy: therapeutic implications. Br J Ophthalmol 2012;96:1285-1290.

-6 Simo R, Hernandez C; European Consortium for the Early Treatment of Diabetic Retinopathy: Neurodegeneration in the diabetic eye: new insights and therapeutic perspectives. Trends Endocrinol Metab 2014;25:23-33.

$\checkmark 7$ Knudtson MD, Lee KE, Hubbard LD, Wong TY, Klein R, Klein BE: Revised formulas for summarizing retinal vessel diameters. Curr Eye Res 2003;27:143-149.

$>8$ Wong TY, Knudtson MD, Klein R, Klein BE, Meuer SM, Hubbard LD: Computer-assisted measurement of retinal vessel diameters in the Beaver Dam Eye Study: methodology, correlation between eyes, and effect of refrac- tive errors. Ophthalmology 2004;111:11831190.

-9 Grauslund J, Hodgson L, Kawasaki R, Green A, Sjolie AK, Wong TY: Retinal vessel calibre and micro- and macrovascular complications in type 1 diabetes. Diabetologia 2009;52: 2213-2217.

10 Klein R, Klein BE, Moss SE, Wong TY: Retinal vessel caliber and microvascular and macrovascular disease in type 2 diabetes. XXI. The Wisconsin Epidemiologic Study of Diabetic Retinopathy. Ophthalmology 2007;114:1884-1892.

11 Ding J, Cheung CY, Ikram MK, Zheng YF, Cheng CY, Lamoureux EL, Tai ES, Subramaniam T, Wong TY: Early retinal arteriolar changes and peripheral neuropathy in diabetes. Diabetes Care 2012;35:1098-1104.

-12 Sabanayagam C, Tai ES, Lee J, Lim SC, Wong TY: Retinal vessel caliber and peripheral neuropathy in diabetic participants. Microcirculation 2010;17:297-302.

13 Wong TY, Shankar A, Klein R, Klein BE: Retinal vessel diameters and the incidence of gross proteinuria and renal insufficiency in people with type 1 diabetes. Diabetes 2004;53: 179-184.

14 Broe R, Rasmussen ML, Frydkjaer-Olsen U, Olsen BS, Mortensen HB, Hodgson L, Wong TY, Peto T, Grauslund J: Retinal vessel calibers predict long-term microvascular complications in type 1 diabetes: the Danish Cohort of Pediatric Diabetes 1987 (DCPD1987). Diabetes 2014;63:3906-3914.
15 Bronson-Castain KW, Bearse MA Jr, Neuville J, Jonasdottir S, King-Hooper B, Barez S, Schneck ME, Adams AJ: Adolescents with type 2 diabetes: early indications of focal retinal neuropathy, retinal thinning, and venular dilation. Retina 2009;29:618-626.

16 Bronson-Castain KW, Bearse MA Jr, Neuville J, Jonasdottir S, King-Hooper B, Barez S, Schneck ME, Adams AJ: Early neural and vascular changes in the adolescent type 1 and type 2 diabetic retina. Retina 2012;32:92-102.

17 Luu CD, Szental JA, Lee SY, Lavanya R, Wong TY: Correlation between retinal oscillatory potentials and retinal vascular caliber in type 2 diabetes. Invest Ophthalmol Vis Sci 2010; 51:482-486.

18 Harrison WW, Chang A, Cardenas MG, Bearse MA Jr, Schneck ME, Barez S, Adams AJ: Blood pressure, vessel caliber, and retinal thickness in diabetes. Optom Vis Sci 2012;89: 1715-1720.

19 Grading diabetic retinopathy from stereoscopic color fundus photographs - an extension of the modified Airlie House classification. ETDRS report No 10. Early Treatment Diabetic Retinopathy Study Research Group. Ophthalmology 1991;98:786-806.

20 Sull AC, Vuong LN, Price LL, Srinivasan VJ, Gorczynska I, Fujimoto JG, Schuman JS, Duker JS: Comparison of spectral/Fourier domain optical coherence tomography instruments for assessment of normal macular thickness. Retina 2010;30:235-245.
Retinal Vessel Calibre Correlates with Neurodegeneration in Type 2 Diabetes 
21 Hood DC, Bach M, Brigell M, Keating D, Kondo M, Lyons JS, Marmor MF, McCulloch DL, Palmowski-Wolfe AM; International Society for Clinical Electrophysiology of Vision: ISCEV standard for clinical multifocal electroretinography (mfERG) (2011 edition). Doc Ophthalmol 2012;124:1-13.

22 Hubbard LD, Brothers RJ, King WN, Clegg LX, Klein R, Cooper LS, Sharrett AR, Davis MD, Cai J: Methods for evaluation of retinal microvascular abnormalities associated with hypertension/sclerosis in the Atherosclerosis Risk in Communities Study. Ophthalmology 1999;106:2269-2280.

-23 Tsai AS, Wong TY, Lavanya R, Zhang R, Hamzah H, Tai ES, Cheung CY: Differential association of retinal arteriolar and venular caliber with diabetes and retinopathy. Diabetes Res Clin Pract 2011;94:291-298.

24 Cheung CY, Lamoureux E, Ikram MK, Sasongko MB, Ding J, Zheng Y, Mitchell P, Wang JJ, Wong TY: Retinal vascular geome- try in Asian persons with diabetes and retinopathy. J Diabetes Sci Technol 2012;6:595605.

25 Klein R, Klein BE, Moss SE, Wong TY, Sharrett AR: Retinal vascular caliber in persons with type 2 diabetes: the Wisconsin Epidemiological Study of Diabetic Retinopathy. Part XX. Ophthalmology 2006;113:14881498.

26 Klein R, Klein BE, Moss SE, Wong TY, Hubbard L, Cruickshanks KJ, Palta M: Retinal vascular abnormalities in persons with type 1 diabetes: the Wisconsin Epidemiologic Study of Diabetic Retinopathy. Part XVIII. Ophthalmology 2003;110:2118-2125.

27 Cheung N, Rogers SL, Donaghue KC, Jenkins AJ, Tikellis G, Wong TY: Retinal arteriolar dilation predicts retinopathy in adolescents with type 1 diabetes. Diabetes Care 2008;31: 1842-1846.

28 Alibrahim E, Donaghue KC, Rogers S, Hing S, Jenkins AJ, Chan A, Wong TY: Retinal vas- cular caliber and risk of retinopathy in young patients with type 1 diabetes. Ophthalmology 2006;113:1499-1503.

29 Klein R, Klein BE, Moss SE, Wong TY, Hubbard L, Cruickshanks KJ, Palta M: The relation of retinal vessel caliber to the incidence and progression of diabetic retinopathy. XIX. The Wisconsin Epidemiologic Study of Diabetic Retinopathy. Arch Ophthalmol 2004; 122:76-83.

30 Roy MS, Klein R, Janal MN: Retinal venular diameter as an early indicator of progression to proliferative diabetic retinopathy with and without high-risk characteristics in African Americans with type 1 diabetes mellitus. Arch Ophthalmol 2011;129:8-15.

31 Van Dijk HW, Verbraak FD, Kok PH, Stehouwer M, Garvin MK, Sonka M, DeVries JH, Schlingemann RO, Abramoff MD: Early neurodegeneration in the retina of type 2 diabetic patients. Invest Ophthalmol Vis Sci 2012;53: 2715-2719. 